\title{
Efeito de fungos micorrízicos arbusculares no desenvolvimento do abacateiro(1)
}

\author{
Samar Velho da Silveira(2), Paulo Vítor Dutra de Souza(2) e Otto Carlos Koller(2)
}

\begin{abstract}
Resumo - O objetivo deste trabalho foi determinar a influência da inoculação de seis espécies de fungos micorrízicos arbusculares (FMA) (Glomus clarum, G. etunicatum, G. manihotis, Acaulospora scrobiculata, Scutellospora heterogama e Gigaspora margarita) sobre o desenvolvimento vegetativo de mudas de abacateiro (Persea sp.), nas fases de porta-enxerto, de muda enxertada e de muda no pomar. A influência dos FMA em abacateiros foi variável conforme a espécie do endófito em estudo. As espécies $S$. heterogama, A. scrobiculata, G. etunicatum e G. clarum colonizaram mais intensamente o sistema radicular dos abacateiros, promovendo melhor desenvolvimento vegetativo das plantas, na fase de porta-enxerto, ao longo do período de produção da muda e após o transplante para pomar.
\end{abstract}

Termos para indexação: Persea americana, endomicorriza, inoculação, produção de mudas.

\section{Effect of arbuscular mycorrhizal fungi on growth of avocado}

\begin{abstract}
The objective of this work was to evaluate the influence of six arbuscular mycorrhizal fungi (AMF) (Glomus clarum, G. etunicatum, G. manihotis, Acaulospora scrobiculata, Scutellospora heterogama and Gigaspora margarita) on the vegetative growth, of grafted avocado plants (Persea sp.), in the rootstocks phase, grafted plant and after transplant to the orchard. The influence of AMF in avocado plants varyed according to the endophytic mycorrhiza species under study. The species S. heterogama, A. scrobiculata, G. etunicatum and G. clarum were more effective in root colonization, promoting better vegetative growth of plants on the rootstock phase, during the plant production period and after the transplanting to the orchard.
\end{abstract}

Index terms: Persea americana, endomycorrhizae, inoculation, scion production.

\section{Introdução}

Fungos micorrízicos arbusculares (FMA) são organismos benéficos às plantas que se associam às raízes e proporcionam redução de danos no transplante, maior índice de pegamento das mudas, redução no tempo de formação, aumento na absorção de alguns nutrientes e maior produção de substâncias de reserva (Haas \& Menge, 1990; Azcón-Aguilar et al., 1992). Os FMA são influenciados pelas condições do meio ambiente. À medida que estas variam, e de acordo com a espécie de fungo, a eficiência

\footnotetext{
(1) Aceito para publicação em 19 de julho de 2002.

Extraído da dissertação de mestrado do primeiro autor apresentada à Universidade Federal do Rio Grande do Sul (UFRGS), Porto Alegre, RS.

(2)UFRGS, Fac. de Agronomia, Dep. de Horticultura e Silvicultura, Caixa Postal 776, CEP 91710-000 Porto Alegre, RS. E-mail: svs@cidadeinternet.com.br, pvdsouza@vortex.ufrgs.br, ockoller@adufrgs.ufrgs.br
}

da simbiose planta/FMA também varia (Powell \& Bagyaraj, 1984; Allen, 1991).

Em fruteiras que passam por fases de sementeira e viveiro, há maior facilidade de inoculação de FMA do que em culturas anuais, em virtude da menor quantidade de inoculante requerida. A produção de mudas de abacateiro ocorre em recipientes, com o emprego de substratos desinfestados, cuja finalidade é a eliminação dos patógenos de solo, verificando também a eliminação dos FMA. A ausência de FMA pode acarretar prejuízo ao abacateiro porque as hifas dos FMA comportam-se como pêlos radiculares, aumentando a área de absorção de nutrientes das raízes do abacateiro que possuem poucos pêlos radiculares (Silva \& Siqueira, 1991). Se por um lado este efeito pode ser modulado pela fertilidade do substrato, por outro, a aplicação de fertilizantes pode aumentar os custos de produção da muda e o impacto ambiental (Chu et al., 2001; Costa et al., 2001). 
Menge et al. (1980), testando a inoculação de Glomus fasciculatum Gerd. em plantas de abacateiro micropropagadas, verificaram crescimento de $49 \%$ a $254 \%$ superior aos das plantas não micorrizadas. Vidal et al. (1992), ao inocularem G. fasciculatum em plantas micropropagadas do abacateiro, observaram que houve aumento na concentração de $\mathrm{N}, \mathrm{P}$ e K no sistema radicular, aumento no número de folhas, no peso da massa seca de raízes e de parte aérea, na sobrevivência de mudas repicadas e na relação parte aérea/raiz, em comparação com mudas sem inoculação. Silva \& Siqueira (1991), testando a inoculação de espécies de FMA em porta-enxertos de abacateiro, verificaram, nas mudas submetidas à inoculação de Scutellospora heterogama Nicol. \& Gerd., produção de matéria seca $24 \%$ maior do que nas mudas não micorrizadas.

O objetivo deste trabalho foi determinar a influência da inoculação de seis espécies de FMA no desenvolvimento vegetativo de mudas de abacateiro nas fases de porta-enxerto, de muda enxertada e após o transplante ao pomar.

\section{Material e Métodos}

O experimento foi realizado no setor de Horticultura da Estação Experimental Agronômica da Universidade Federal do Rio Grande do Sul, Km 146 da BR 290, Município de Eldorado do Sul, RS, no período de setembro de 1997 a janeiro de 1999.

O experimento abrangeu três fases: porta-enxerto, muda enxertada e campo. $\mathrm{O}$ delineamento experimental utilizado foi o de blocos casualizados, com sete tratamentos e quatro repetições, totalizando 28 parcelas, cada uma com 15 plantas.

Sementes de abacate, provenientes de um mesmo péfranco, foram semeadas em leito de areia, em casa de vegetação. A areia foi previamente desinfestada com solução de formaldeído, a 7\%. Após a germinação e emergência, ocorrida em torno de 18 dias, as plântulas, cujos epicótilos apresentavam aproximadamente $5 \mathrm{~cm}$ de comprimento, foram repicadas para sacos de plástico pretos com capacidade de $5 \mathrm{~L}$, contendo substrato constituído de solo argiloso:areia:resíduo decomposto de casca de acácia-negra (2:2:1, v:v:v). Esta fase foi conduzida em telado de sombrite $(50 \%)$. O solo utilizado na composição do substrato foi classificado como Argissolo Vermelho distrófico típico, unidade de mapeamento São
Gerônimo (Embrapa, 1999). A areia utilizada possuía granulometria média (partículas $<1 \mathrm{~mm}$ ). O resíduo decomposto de casca de acácia-negra (Acacia mearnsii De Wild.) foi coletado em um depósito a céu aberto da empresa produtora de tanino TANAC S/A, localizada no Município de Montenegro, RS, e peneirado em malha de $5 \mathrm{~mm}$, para uniformizar a sua granulometria. O solo, a areia e o resíduo decomposto de casca de acácia-negra sofreram prévia desinfestação com solução de formaldeído, a 7\%.

Com base na análise química do substrato (Tabela 1), realizada no Laboratório de Análises de Solos e Tecidos da Faculdade de Agronomia, UFRGS, e conforme recomendação da Comissão de Fertilidade do Solo RS/SC (1994), aplicou-se dose de fosfato natural de Arad (33\% de $\mathrm{P}_{2} \mathrm{O}_{5}$ total e $2 \%$ de $\mathrm{P}_{2} \mathrm{O}_{5}$ solúvel em ácido cítrico), para atingir uma concentração de $20 \mathrm{mg} \mathrm{L}^{-1}$; o teor de $\mathrm{K}_{2} \mathrm{O}$ foi corrigido com $\mathrm{KCl}\left(60 \%\right.$ de $\left.\mathrm{K}_{2} \mathrm{O}\right)$, para atingir uma concentração de $80 \mathrm{mg} \mathrm{L}^{-1}$; corrigiu-se a acidez com $\mathrm{CaCO}_{3}$ para atingir pH 6,0. Não houve necessidade de correção dos níveis de micronutrientes.

Os tratamentos consistiram na inoculação de Glomus clarum Nicol. \& Schenck (50 esporos/g de solo seco), G. etunicatum Becker \& Gerd. (50 esporos/g de solo seco), G. manihotis How., Siev \& Schenck (40 esporos/g de solo seco), Acaulospora scrobiculata Trappe (45 esporos/g de solo seco), Scutellospora heterogama Nicol. \& Gerd. (30 esporos/g de solo seco), Gigaspora margarita Becker \& Hall (30 esporos/g de solo seco) e na testemunha, sem inoculação. Os inóculos utilizados procederam do banco de espécies do Departamento de Horticultura e Silvicultura, da Faculdade de Agronomia da UFRGS. A inoculação das espécies de FMA foi feita com a adição de $30 \mathrm{~g}$ de solo inóculo, contendo esporos, hifas e colônias de FMA em raízes de aveia (Avena strigosa Schreb.). Cada saco de polietileno foi preenchido até a metade de sua altura com o substrato; a seguir, adicionou-se o inóculo formando uma camada e, finalmente, completou-se o volume do saco com substrato. Imediatamente após, efetuou-se a repicagem dos porta-enxertos do leito de areia para os respectivos sacos de polietileno.

Nas fases de porta-enxerto e de muda enxertada, utilizaram-se cinco plantas por parcela/repetição, para realizar todas as análises em cada uma destas fases, totalizando 20 plantas por tratamento em cada fase. Na fase de muda no pomar, em virtude de perdas ocorridas desde a repicagem das plântulas até o momento de levá-las ao pomar, utilizaram-se duas plantas por parcela e três repetições, em um total de seis plantas analisadas por tratamento.

Dois meses após a repicagem, mediu-se a altura das plantas, do colo até o ápice do ramo principal, e o diâmetro do caule principal, na altura do colo, e foram determi- 
nados o peso da matéria fresca e seca da parte aérea e raízes, área foliar, conteúdo de $\mathrm{P}$ da parte aérea e colonização radicular com FMA.

A área foliar foi determinada através da passagem de cada folha em um medidor de área foliar. A parte aérea de cada planta (folhas e ramos) foi lavada com água destilada, secada a $60^{\circ} \mathrm{C}$, até peso constante, moída em moinho acoplado com peneira de 20 malhas por polegada e encaminhada ao Laboratório de Análises de Solos e Tecidos da Faculdade de Agronomia, UFRGS, para determinação de fósforo.

Na determinação da colonização radicular, utilizou-se a técnica de coloração de raízes (Phillips \& Hayman, 1970 modificado, citado por Colozzi-Filho \& Balota, 1994), seguida da medição do porcentual e da intensidade de colonização, determinada segundo Nemec (1992), a qual consiste em quantificar e classificar a presença de hifas, vesículas e arbúsculos. No caso das hifas, os seguintes índices foram atribuídos: 0 (inexistência); 1 (escasso desenvolvimento de hifas no segmento); 2 (moderado) e 3 (intenso desenvolvimento de hifas). As vesículas e os arbúsculos, por sua vez, foram classificados como 0 (inexistência de estruturas); 1 (presença de 1 até 50 estruturas); 2 (51 até 100 estruturas) e 3 (mais de 100 estruturas). A porcentagem de colonização de raízes por FMA foi obtida pela divisão do número de segmentos de raízes colonizadas pelo número total de segmentos de raízes observadas.

Após a primeira avaliação, as dez plantas restantes de cada parcela foram enxertadas com a cultivar Carmem utilizando-se de garfagem de fenda cheia. Sete meses após a enxertia, foram realizadas as mesmas avaliações efetuadas anteriormente com os porta-enxertos com algumas modificações: o diâmetro foi medido imediatamente acima do ponto de enxertia e acrescentou-se contagem do número de folhas e superfície foliar.
As linhas de plantio foram preparadas com espaçamento de $6 \mathrm{~m}$ entre linhas e, com base no laudo da análise química do solo, realizada previamente no Laboratório de Análises de Solos e Tecidos da Faculdade de Agronomia, UFRGS, foram aplicadas no solo $3 \mathrm{tha}^{-1}$ de calcário (PRNT 75\%), visando atingir pH 6,0 conforme recomendação da Comissão de Fertilidade do Solo RS/SC (1994); $100 \mathrm{~kg} \mathrm{ha}^{-1}$ de $\mathrm{P}_{2} \mathrm{O}_{5}$ e $50 \mathrm{~kg} \mathrm{ha}^{-1} \mathrm{de} \mathrm{K}_{2} \mathrm{O}$, em uma faixa de 2,5 m de largura, ao longo de toda a linha de plantio. Este solo possui a mesma classificação descrita anteriormente para solo utilizado na composição do substrato. As covas, com $30 \mathrm{~cm}$ de largura e $35 \mathrm{~cm}$ de profundidade, foram abertas com um espaçamento de $3 \mathrm{~m}$ entre covas na linha.

No dia 9/9/1998, foi realizado o plantio, no campo, de duas plantas por parcela e três repetições, em um total de seis plantas por tratamento, no delineamento experimental de blocos casualizados.

Antes do plantio, as mudas foram podadas em torno de $20 \mathrm{~cm}$ acima do ponto de enxertia e foram retiradas todas as folhas, para reduzir a perda de água por transpiração. Quatro meses após o plantio no campo, realizaram-se as avaliações de altura do colo ao ápice do ramo principal, diâmetro do caule (logo acima do ponto de enxertia) e número de folhas por planta.

Os resultados obtidos foram submetidos à análise de variância e as médias comparadas pelo teste de Duncan a 5\% de probabilidade. Em virtude da presença de valores iguais a zero, os dados referentes a quantificação de estruturas de FMA nas raízes (presença de hifas, arbúsculos e vesículas) foram transformados por raiz quadrada de $\mathrm{x}+1$.

\section{Resultados e Discussão}

Os dados de fertilidade do substrato, após correção e inoculação, mostram que os substratos cultivados com todas as espécies de FMA apresentaram

Tabela 1. Análise química do substrato, dois meses após a correção da fertilidade e inoculação das espécies de fungos micorrízicos arbusculares (FMA), em mudas de abacateiro. UFRGS, Porto Alegre, 1997(1).

\begin{tabular}{lcccccccr}
\hline Espécies de FMA & $\begin{array}{c}\mathrm{MO} \\
(\%)\end{array}$ & $\begin{array}{c}\mathrm{P} \\
\left(\mathrm{mg} \mathrm{L}^{-1}\right)\end{array}$ & $\begin{array}{c}\mathrm{K} \\
\left(\mathrm{mg} \mathrm{L}^{-1}\right)\end{array}$ & $\begin{array}{c}\mathrm{Ca} \\
\left(\mathrm{cmol}_{\mathrm{c}}{ }^{-1}\right)\end{array}$ & $\begin{array}{c}\mathrm{Mg} \\
\left(\mathrm{cmol}_{\mathrm{c}} \mathrm{L}^{-1}\right)\end{array}$ & $\begin{array}{c}\mathrm{S} \\
\left(\mathrm{mg} \mathrm{L}^{-1}\right)\end{array}$ & $\begin{array}{c}\mathrm{pH} \\
\left(\mathrm{cmol}_{\mathrm{c}} \mathrm{L}^{-1}\right)\end{array}$ \\
\hline Glomus clarum & 3,5 & 16,0 & 60,0 & 6,3 & 1,2 & 5,8 & 6,6 & 9,0 \\
Scutellospora heterogama & 3,5 & 15,0 & 54,0 & 6,0 & 1,1 & 8,6 & 6,9 & 8,4 \\
Glomus etunicatum & 3,5 & 18,0 & 61,0 & 6,5 & 1,3 & 9,2 & 6,4 & 9,4 \\
Acaulospora scrobiculata & 3,6 & 14,0 & 63,0 & 6,2 & 1,2 & 8,0 & 6,7 & 8,9 \\
Gigaspora margarita & 3,9 & 19,0 & 57,0 & 8,0 & 1,2 & 5,9 & 6,8 & 10,6 \\
Glomus manihotis & 3,7 & 16,0 & 63,0 & 6,5 & 1,3 & 5,0 & 6,7 & 9,3 \\
Testemunha & 3,6 & 20,0 & 80,0 & 6,9 & 1,3 & 12,0 & 6,3 & 9,8 \\
\hline
\end{tabular}

${ }^{(1)}$ Análise química do substrato anterior à inoculação: $\mathrm{MO}, 5,2 \% ; \mathrm{P}, 6 \mathrm{mg} \mathrm{L}-1 ; \mathrm{K}, 42 \mathrm{mg} \mathrm{L}^{-1} ; \mathrm{Ca}, 7,5 \mathrm{cmol}_{\mathrm{c}} \mathrm{L}^{-1} ; \mathrm{Mg}_{0}, 8 \mathrm{cmol}_{\mathrm{c}} \mathrm{L}^{-1} ; \mathrm{S}, 8,1 \mathrm{mg} \mathrm{L}^{-1}$; $\mathrm{pH}, 5,4$ e CTC, $9,5 \mathrm{cmol}_{\mathrm{c}} \mathrm{L}^{-1}$. 
quantidades absolutas de $\mathrm{P}, \mathrm{K}$ e S menores do que o da testemunha (Tabela 1). Este fato pode ser um indicativo de que as plantas micorrizadas absorveram mais nutrientes, com a ressalva de que, em virtude da utilização desses nutrientes no sistema radicular e da pouca translocação para a parte aérea de alguns deles, não há correspondência direta com teores na parte aérea.

As espécies G. clarum, S. heterogama, G. etunicatum e A. scrobiculata propiciaram altura de planta superior $(\mathrm{p} \leq 0,05)$ à da testemunha na fase de porta-enxerto, e observou-se que G. clarum e A. scrobiculata também propiciaram maior altura em relação à testemunha, na fase de muda enxertada e muda no pomar, respectivamente (Tabela 2). A altura de plantas que receberam inóculo de G. margarita e G. manihotis não diferiu da testemunha em nenhuma das três fases. Com relação ao diâmetro, não houve diferença entre tratamentos na primeira fase, mas plantas com inoculação da espécie S. heterogama apresentaram um diâmetro superior ao da testemunha na segunda fase e plantas com inoculação das espécies G. clarum, S. heterogama, G. etunicatum e A. scrobiculata apresentaram diâmetro superior ao da testemunha na fase de muda no pomar. Plantas que receberam inóculo de G. margarita e G. manihotis não diferiram da testemunha, em relação ao diâmetro, em nenhuma fase (Tabela 2).

Menge et al. (1978, 1980) e Vidal et al. (1992) também constataram, em abacateiro, maior altura da par- te aérea em mudas que receberam inóculos e confirmaram que a utilização de mudas previamente submetidas a inoculação de espécies de FMA (neste caso de G. clarum, S. heterogama, G. etunicatum e A. scrobilculata) permite seu estabelecimento e desenvolvimento mais rápido no viveiro (Menge et al., 1980; Silva \& Siqueira, 1991) e no pomar. Essa resposta diferenciada do abacateiro, de acordo com a espécie de FMA, deve-se, provavelmente, à afinidade colonizador-hospedeiro, já citada por Menge et al. (1980) e Haas \& Menge (1990), e ao fato de as espécies de fungos micorrízicos responderem de forma diferenciada aos fatores climáticos e às características químicas e físicas do solo (Haas \& Menge, 1990; Silva \& Siqueira, 1991).

A área foliar dos porta-enxertos de abacateiro que receberam inóculo de $S$. heterogama, G. etunicatum e A. scrobiculata foi superior à área foliar da testemunha (Tabela 3) e, na fase de muda pronta, as espécies $S$. heterogama e $A$. scrobiculata continuaram proporcionando maior área foliar em relação à testemunha. A espécie G. manihotis não propiciou área foliar diferente da testemunha em nenhuma fase, enquanto plantas que receberam inóculo de G. margarita apresentaram área foliar inferior à da testemunha na fase de porta-enxerto e similar na fase de muda pronta.

$\mathrm{Na}$ fase de muda enxertada, as plantas que receberam inóculo de S. heterogama apresentaram número de folhas por planta superior ao da testemunha (Tabela 3). G. clarum, propiciou o menor número

Tabela 2. Altura e diâmetro do caule da parte aérea de porta-enxerto, de mudas enxertadas no viveiro e no pomar de abacateiro cultivar Carmem, submetidas à inoculação de seis espécies de fungos micorrízicos arbusculares (FMA). UFRGS, Eldorado do Sul, RS, 1999(1).

\begin{tabular}{|c|c|c|c|c|c|c|}
\hline \multirow[t]{2}{*}{ Espécies de FMA } & \multicolumn{2}{|c|}{ Porta-enxerto $^{(2)}$} & \multicolumn{2}{|c|}{ Muda enxertada $^{(3)}$} & \multicolumn{2}{|c|}{ Muda no pomar $^{(4)}$} \\
\hline & $\begin{array}{l}\text { Altura } \\
(\mathrm{cm})\end{array}$ & $\begin{array}{c}\text { Diâmetro } \\
(\mathrm{mm})\end{array}$ & $\begin{array}{l}\text { Altura } \\
(\mathrm{cm})\end{array}$ & $\begin{array}{c}\text { Diâmetro } \\
(\mathrm{mm})\end{array}$ & $\begin{array}{c}\text { Altura } \\
(\mathrm{cm})\end{array}$ & $\begin{array}{c}\text { Diâmetro } \\
(\mathrm{mm})\end{array}$ \\
\hline Glomus clarum & $24,10 \mathrm{ab}$ & 6,40 & $30,47 a$ & $8,15 b$ & $43,54 \mathrm{ab}$ & $10,80 \mathrm{a}$ \\
\hline Scutellospora heterogama & $24,67 \mathrm{a}$ & 6,50 & $25,16 a b$ & $10,59 a$ & $38,05 \mathrm{abc}$ & $10,37 \mathrm{a}$ \\
\hline Glomus etunicatum & $24,15 \mathrm{ab}$ & 6,30 & $27,37 \mathrm{ab}$ & $8,26 b$ & $40,08 \mathrm{abc}$ & $10,75 a$ \\
\hline Acaulospora scrobiculata & $23,72 \mathrm{ab}$ & 6,60 & $24,89 \mathrm{ab}$ & $9,53 \mathrm{ab}$ & $44,92 \mathrm{a}$ & $10,08 \mathrm{a}$ \\
\hline Gigaspora margarita & $22,87 b c$ & 6,60 & $23,53 b$ & $9,57 \mathrm{ab}$ & $33,63 \mathrm{c}$ & $9,63 \mathrm{ab}$ \\
\hline Glomus manihotis & $21,69 c$ & 6,50 & $23,04 b$ & $8,26 \mathrm{~b}$ & $37,44 b c$ & $9,79 \mathrm{ab}$ \\
\hline Testemunha & $21,92 \mathrm{c}$ & 6,50 & $23,03 b$ & $8,86 b$ & $34,02 \mathrm{c}$ & $8,72 b$ \\
\hline $\mathrm{CV}(\%)$ & 14,0 & 16,1 & 13,7 & 11,3 & 10,4 & 6,7 \\
\hline
\end{tabular}

${ }^{(1)}$ Médias seguidas de mesma letra, na coluna, não diferem entre si a $5 \%$ de probabilidade, pelo teste de Duncan. (2)Medição realizada dois meses após a inoculação com FMA. ${ }^{(3)}$ Medição realizada sete meses após a enxertia. ${ }^{(4)}$ Medição realizada quatro meses após transplante ao pomar. 
de folhas por planta; os demais tratamentos, inclusive testemunha, apresentaram um número de folhas intermediário entre S. heterogama e G. clarum. $\mathrm{Na}$ fase de muda no pomar, no entanto, as plantas submetidas a inoculação de G. clarum apresentaram um maior número de folhas por planta em relação à testemunha (Tabela 3). As outras espécies apresentaram resposta intermediária entre G. clarum e a testemunha, à exceção de G. margarita, cuja resposta tendeu a ser inferior à da testemunha, demonstrando a habilidade dos FMA em acelerar o desenvolvimento vegetativo das plantas e o fato de que algumas espécies de FMA promovem a produção de maior número de folhas em mudas de abacateiro (Vidal et al., 1992).

Com exceção das plantas que receberam inóculo de G. manihotis, aquelas que receberam inóculos das demais espécies de FMA apresentaram um aumento no tamanho médio (superfície) das folhas de abacateiro (Tabela 3). Algumas espécies de FMA têm a capacidade de incrementar o tamanho das folhas de plantas frutíferas (Souza et al., 1998), o que favorece aumento na área fotossinteticamente ativa.

Quanto ao peso da matéria seca da parte aérea, somente os porta-enxertos submetidos a inoculação de $S$. heterogama foram superiores à testemunha (Tabela 4). Os porta-enxertos que receberam inóculos das demais espécies não diferiram da testemunha. Com relação ao peso da matéria seca de raízes, o tratamento $S$. heterogama foi estatisticamente superior à testemunha, G. margarita foi inferi- or e os demais tratamentos não diferiram significativamente da testemunha.

Na fase de muda enxertada, S. heterogama e G. etunicatum proporcionaram peso da parte aérea superior ao da testemunha, com uma diferença de $18,5 \%$. As plantas que receberam inóculo das demais espécies de FMA não diferiram da testemunha (Tabela 4).

Estes resultados confirmam que algumas espécies de FMA induzem maior peso da matéria seca da parte aérea em mudas de abacateiro (Vidal et al., 1992). De forma geral, os resultados obtidos no porta-enxerto mantiveram-se ao longo do período de cultivo, confirmando os resultados de Souza et al. (1998), com citros, em que plantas, que receberam inóculo de FMA apresentaram seu desenvolvimento vegetativo acelerado desde a fase de porta-enxerto até a muda enxertada.

Em relação ao peso da matéria seca de raízes, na muda enxertada, não ocorreu diferença estatística entre os tratamentos (Tabela 4). Nesse sentido, Vidal et al. (1992) encontraram uma relação peso de raiz/ peso da parte aérea significativamente menor em plantas micorrizadas do que em plantas não micorrizadas, situação semelhante à ocorrida na fase de muda enxertada (Tabela 4).

Na fase de porta-enxerto, não houve diferença significativa no conteúdo de $\mathrm{P}$ da parte aérea entre os tratamentos, mas na fase de muda enxertada, as plantas que receberam inóculo das espécies $S$. heterogama, G. etunicatum e A. scrobiculata apresentaram quan-

Tabela 3. Área foliar por planta, número de folhas por planta e superfície por folha de mudas de abacateiro, cultivar Carmem, em três fases de desenvolvimento, submetidas à inoculação de seis espécies de fungos micorrízicos arbusculares (FMA). UFRGS, Eldorado do Sul, RS,1999(1).

\begin{tabular}{|c|c|c|c|c|c|}
\hline \multirow[t]{2}{*}{ Espécies de FMA } & \multirow{2}{*}{$\begin{array}{c}\text { Porta-enxerto }^{(2)} \\
\text { Área } \\
\text { foliar/planta } \\
\left(\mathrm{cm}^{2}\right)\end{array}$} & \multicolumn{3}{|c|}{ Muda enxertada ${ }^{(3)}$} & \multirow{2}{*}{$\begin{array}{c}\text { Pomar }^{(4)} \\
\text { Número de } \\
\text { folhas/planta }\end{array}$} \\
\hline & & $\begin{array}{l}\text { Número de } \\
\text { folhas/planta }\end{array}$ & $\begin{array}{l}\text { Superfície /folha } \\
\left(\mathrm{cm}^{2}\right)\end{array}$ & $\begin{array}{c}\text { Área } \\
\text { foliar/planta } \\
\left(\mathrm{cm}^{2}\right)\end{array}$ & \\
\hline Glomus clarum & $465,37 \mathrm{c}$ & $32,77 \mathrm{c}$ & $32,90 \mathrm{a}$ & $1078,13 \mathrm{ab}$ & $61,83 a$ \\
\hline Scutellospora heterogama & $580,82 \mathrm{a}$ & $41,65 \mathrm{a}$ & $30,57 \mathrm{a}$ & $1273,24 \mathrm{a}$ & $58,00 \mathrm{ab}$ \\
\hline Glomus etunicatum & $512,08 \mathrm{~b}$ & $35,90 \mathrm{~b}$ & $32,72 \mathrm{a}$ & $1174,65 \mathrm{ab}$ & $59,67 \mathrm{ab}$ \\
\hline Acaulospora scrobiculata & $524,57 \mathrm{~b}$ & $38,15 b$ & $32,02 \mathrm{a}$ & $1221,56 a$ & $47,50 \mathrm{abc}$ \\
\hline Gigaspora margarita & $426,07 \mathrm{~d}$ & $38,30 \mathrm{~b}$ & $30,81 \mathrm{a}$ & $1180,02 \mathrm{ab}$ & $39,83 \mathrm{c}$ \\
\hline Glomus manihotis & $479,99 \mathrm{c}$ & $37,41 \mathrm{~b}$ & $26,27 b$ & $982,76 \mathrm{c}$ & $46,15 \mathrm{abc}$ \\
\hline Testemunha & $460,95 \mathrm{c}$ & $38,66 \mathrm{~b}$ & $27,04 \mathrm{~b}$ & $1045,37 b c$ & $40,16 \mathrm{bc}$ \\
\hline CV (\%) & 9,63 & 7,79 & 10,12 & 9,31 & 10,39 \\
\hline
\end{tabular}


tidades de $\mathrm{P}$ superiores à da testemunha, enquanto as que receberam inóculo das demais espécies não diferiram da testemunha (Tabela 4). Este fato confirma a capacidade dos FMA em propiciar às plantas maior absorção de elementos de baixa mobilidade no solo, dependendo da afinidade colonizador-hospedeiro, visto que nem todas as espécies de FMA apresentam essa resposta em abacateiro (Menge et al., 1980 e Silva \& Siqueira, 1991).

Na fase de porta-enxerto, não houve diferenças significativas quanto à presença de hifas entre as espécies de FMA estudadas, mas apenas uma tendência de superioridade das espécies G. clarum, G. etunicatum e A. scrobiculata (Tabela 5). Em relação à presença de arbúsculos, na fase de porta-enxerto, as espécies G. clarum, S. heterogama, G. etunicatum e A. scrobiculata apresentaram níveis superiores aos das espécies G. margarita e G. manihotis e estas, aos da testemunha. Nesta fase, somente G. etunicatum e A. scrobiculata apresentaram vesículas. No entanto, esperava-se que G. clarum e G. manihotis tivessem formado estas estruturas de reserva, o que não ocorreu, provavelmente, por causa do período de tempo desde a inoculação até a avaliação, já que, na segunda fase, G. clarum passou a apresentar vesículas. A presença de hifas, vesículas e arbúsculos nos diversos tratamentos foi mais elevada na segunda fase (Tabela 5), em comparação com a primeira. Este comportamento era esperado e deve-se, principalmente, ao maior período de cultivo das mudas em seus respectivos recipientes.
A porcentagem de colonização do sistema radicular não variou entre as espécies de FMA estudadas (Tabela 5). O fato de ter-se encontrado estruturas de FMA nas plantas testemunha, pode ser explicado, provavelmente, por contaminação decorrente da proximidade com plantas micorrizadas. Esta presença foi incipiente e considerada normal, pois já ocorreu em outros estudos (Schmitz, 1998).

$\mathrm{Na}$ fase de porta-enxerto, a intensidade de arbúsculos foi a variável mais determinante para caracterizar a eficiência mutualística, já que as quatro espécies de melhor desempenho sobre o desenvolvimento vegetativo ( $S$. heterogama, A. scrobiculata, G. clarum e G. etunicatum) foram as que apresentaram maiores intensidades de arbúsculos nas raízes. Portanto, essas espécies dispuseram de maior número de pontos de troca, fornecendo mais nutrientes e água às plantas, que possibilitou melhor desenvolvimento vegetativo.

Confirmando a tendência verificada nos portaenxertos, as espécies G. clarum, G. etunicatum e A. scrobiculata apresentaram maior quantidade de hifas no sistema radicular em relação às espécies G. margarita e G. manihotis na muda enxertada (Tabela 5). A espécie $S$. heterogama apresentou valores intermediários entre estes extremos e a espécie G. manihotis apresentou a menor intensidade de hifas entre as espécies de FMA estudadas.

A. scrobiculata formou o maior número de arbúsculos entre as espécies de FMA na fase de muda enxertada, seguida por G. clarum, S. heterogama e G. etunicatum. A espécie G. margarita apresentou

Tabela 4. Matéria seca da parte aérea e das raízes e conteúdo de P da parte aérea de porta-enxerto e de mudas enxertadas de abacateiro, cultivar Carmem, submetidas à inoculação de seis espécies de fungos micorrízicos (FMA). UFRGS, Eldorado do Sul, RS, 1999(1).

\begin{tabular}{|c|c|c|c|c|c|c|}
\hline \multirow[t]{3}{*}{ Espécies de FMA } & \multicolumn{3}{|c|}{ Porta-enxerto $^{(2)}$} & \multicolumn{3}{|c|}{ Muda enxertada $^{(3)}$} \\
\hline & \multicolumn{2}{|c|}{ Peso $(\mathrm{g})$} & \multirow{2}{*}{$\begin{array}{c}\mathrm{P}(\mathrm{mg} / \mathrm{pl} .) \\
\text { Parte aérea }\end{array}$} & \multicolumn{2}{|c|}{ Peso (g) } & \multirow{2}{*}{$\frac{\mathrm{P}(\mathrm{mg} / \mathrm{pl} .)}{\text { Parte aérea }}$} \\
\hline & Parte aérea & Raízes & & Parte aérea & Raízes & \\
\hline Glomus clarum & $4,03 \mathrm{bc}$ & $1,89 \mathrm{bc}$ & 5,24 & $77,62 \mathrm{ab}$ & 10,61 & $56,37 \mathrm{c}$ \\
\hline Scutellospora heterogama & $4,77 \mathrm{a}$ & $2,50 \mathrm{a}$ & 6,20 & $82,72 \mathrm{a}$ & 10,78 & $82,71 \mathrm{a}$ \\
\hline Glomus etunicatum & 4,49ab & $1,97 \mathrm{~b}$ & 6,30 & $83,00 \mathrm{a}$ & 11,45 & $74,71 \mathrm{ab}$ \\
\hline Acaulospora scrobiculata & $4,42 \mathrm{ab}$ & $2,09 \mathrm{~b}$ & 5,75 & $70,23 b$ & 10,59 & $70,23 b$ \\
\hline Gigaspora margarita & $3,65 \mathrm{c}$ & $1,50 \mathrm{c}$ & 5,11 & $72,08 b$ & 10,11 & $50,45 c$ \\
\hline Glomus manihotis & $4,11 \mathrm{abc}$ & $1,98 b$ & 5,75 & $67,26 b$ & 10,21 & $53,30 \mathrm{c}$ \\
\hline Testemunha & $3,98 \mathrm{bc}$ & $1,87 \mathrm{~b}$ & 5,97 & $67,52 b$ & 10,30 & $53,91 \mathrm{c}$ \\
\hline $\mathrm{CV}(\%)$ & 8,29 & 10,04 & 12,53 & 9,10 & 9,87 & 13,52 \\
\hline
\end{tabular}

Pesq. agropec. bras., Brasília, v. 37, n. 11, p. 1597-1604, nov. 2002 
quantidade de hifas superior à de G. manihotis, porém inferior à das demais espécies de FMA (Tabela 5).

As espécies G. clarum, G. etunicatum e A. scrobiculata foram as únicas que apresentaram vesículas na fase de muda enxertada, sendo que A. scrobiculata apresentou maior intensidade de vesículas que G. etunicatum, enquanto G. clarum apresentou valores intermediários entre estas duas espécies (Tabela 5). Com relação à porcentagem de colonização do sistema radicular, apesar de as espécies G. clarum, S. heterogama, G. etunicatum e A. scrobiculata terem apresentado, em média, resposta $16 \%$ superior à de G. margarita e G. manihotis, não houve diferença significativa entre as espécies.

O desempenho dos FMA é diretamente afetado pelo pH do solo ou do substrato. Segundo Siqueira (1994), G. margarita predomina em solos ácidos; G. clarum e G. etunicatum têm preferência por solos neutros ou pouco ácidos; enquanto $A$. scrobiculata é indiferente ao $\mathrm{pH}$. Portanto, a elevação do $\mathrm{pH}$ do substrato a 6,0 , considerando o nível mais adequado para bom desenvolvimento do abacateiro, beneficiou as espécies A. scrobiculata, S. heterogama, G. clarum e G. etunicatum em detrimento da espécie G. margarita, que está menos adaptada a esse valor de $\mathrm{pH}$. Refor- çando esta tese, Siqueira \& Franco (1988) citam que essa espécie tem sua ocorrência favorecida em solos com elevado nível de Al, situação verificada em solos ou substratos com pH baixo. Em outras condições de pH e de clima, essa espécie pode ser benéfica ao abacateiro. Assim, Silva \& Siqueira (1991), verificaram aumento de $22,7 \%$ no peso de matéria seca, em mudas de abacateiro que receberam inóculo dessa espécie.

O baixo desempenho da espécie G. manihotis parece não estar relacionado ao $\mathrm{pH}$ do substrato, já que esta espécie apresentou boa porcentagem de colonização e boa presença de hifas, mas baixa eficiência simbiótica do fungo em promover crescimento vegetativo do abacateiro. Várias espécies de FMA exibem infectividade elevada e podem ser pouco efetivas em promover crescimento, absorver e translocar nutrientes para a planta (Haas \& Menge, 1990; Gianinazzi, 1991, citado por Siqueira, 1994). A eficiência da associação entre FMA e plantas frutíferas é regulada pelos genótipos dos dois parceiros micorrízicos, em interação com o ambiente (Costa et al., 2001), o que justifica os resultados obtidos no presente trabalho.

Tabela 5. Presença de hifas, arbúsculos, vesículas e porcentagem de colonização do sistema radicular de porta-enxertos e mudas enxertadas de abacateiro, cultivar Carmem, submetidas a inoculação de seis espécies de fungos micorrízicos arbusculares (FMA). UFRGS, Eldorado do Sul, RS, 1999(1).

\begin{tabular}{llccc}
\hline Espécies de FMA & Hifa & Arbúsculo & Vesícula & Colonização \\
\hline & & \multicolumn{3}{c}{ Porta-enxerto } \\
Glomus clarum & $1,32 \mathrm{ab}$ & $1,43 \mathrm{a}$ & $0,00 \mathrm{~b}$ & $87,10 \mathrm{ab}$ \\
Scutellospora heterogama & $1,21 \mathrm{ab}$ & $1,50 \mathrm{a}$ & $0,00 \mathrm{~b}$ & $87,00 \mathrm{ab}$ \\
Glomus etunicatum & $1,25 \mathrm{ab}$ & $1,40 \mathrm{a}$ & $0,26 \mathrm{ab}$ & $86,91 \mathrm{ab}$ \\
Acaulospora scrobiculata & $1,38 \mathrm{a}$ & $1,64 \mathrm{a}$ & $0,57 \mathrm{a}$ & $91,82 \mathrm{a}$ \\
Gigaspora margarita & $0,81 \mathrm{ab}$ & $0,74 \mathrm{~b}$ & $0,00 \mathrm{~b}$ & $70,90 \mathrm{~b}$ \\
Glomus manihotis & $1,22 \mathrm{ab}$ & $0,70 \mathrm{~b}$ & $0,00 \mathrm{~b}$ & $80,17 \mathrm{ab}$ \\
Testemunha & $0,05 \mathrm{c}$ & $0,04 \mathrm{c}$ & $0,00 \mathrm{~b}$ & $6,50 \mathrm{c}$ \\
\hline CV $(\%)$ & 10,83 & 9,41 & 23,41 & 10,06 \\
\hline & & & Muda enxertada & \\
Glomus clarum & $2,12 \mathrm{ab}$ & $1,89 \mathrm{~b}$ & $2,10 \mathrm{ab}$ & $90,31 \mathrm{a}$ \\
Scutellospora heterogama & $1,94 \mathrm{bc}$ & $2,07 \mathrm{~b}$ & $0,00 \mathrm{c}$ & $91,20 \mathrm{a}$ \\
Glomus etunicatum & $2,45 \mathrm{ab}$ & $2,17 \mathrm{~b}$ & $1,84 \mathrm{~b}$ & $91,50 \mathrm{a}$ \\
Acaulospora scrobiculata & $2,55 \mathrm{a}$ & $2,63 \mathrm{a}$ & $2,29 \mathrm{a}$ & $92,00 \mathrm{a}$ \\
Gigaspora margarita & $1,62 \mathrm{c}$ & $1,61 \mathrm{c}$ & $0,00 \mathrm{c}$ & $77,30 \mathrm{a}$ \\
Glomus manihotis & $0,81 \mathrm{~d}$ & $0,96 \mathrm{~d}$ & $0,00 \mathrm{c}$ & $74,62 \mathrm{a}$ \\
Testemunha & $0,08 \mathrm{e}$ & $0,03 \mathrm{e}$ & $0,00 \mathrm{c}$ & $8,00 \mathrm{~b}$ \\
\hline CV $(\%)$ & 8,31 & 5,87 & 9,43 & 10,00 \\
\hline
\end{tabular}

${ }^{(1)}$ Médias seguidas da mesma letra, na coluna, não diferem entre si a 5\% de probabilidade, pelo teste de Duncan. 


\section{Conclusões}

1. A influência dos FMA em mudas de abacateiroé variável conforme a espécie do endófito em estudo.

2. Scutellospora heterogama, Acaulospora scrobiculata, Glomus etunicatum e G. clarum propiciam melhor desenvolvimento vegetativo desde o período de formação das mudas até o transplante ao campo e também após essa fase.

3. A inoculação de Glomus manihotis não altera o desenvolvimento vegetativo das mudas de abacateiro, enquanto Gigaspora margarita é prejudicial, especialmente na fase de porta-enxerto.

\section{Referências}

ALLEN, M. F. The ecology of mycorrhizae. San Diego: Cambridge University Press, 1991. 184 p.

AZCÓN AGUILAR, C.; BARCELO, A.; VIDAL, M. T.; VINA, G. Further studies on the influence of mycorrhiza on growth and development of micropropagated avocado plants. Agronomie, Paris, v. 46, n. 12, p. 837-840, mai 1992.

CHU, E. Y.; MÖLLER, M. R. F.; CARVALHO, J. G. Efeito da inoculação micorrízica em mudas de gravioleira em solo fumigado e não fumigado. Pesquisa Agropecuária Brasileira, Brasília, v. 36, n. 4, p. 671-680, abr. 2001.

COLOZZI FILHO, A.; BALOTA, E. L. Micorrizas arbusculares. In: HUNGRIA, M.; ARAUJO, R. S. (Ed.). Manual de métodos empregados em microbiologia agrícola. Brasília: Embrapa, 1994. p. 383-418.

COMISSÃO DE FERTILIDADE DO SOLO RS/SC (Passo Fundo, RS). Recomendações de adubação e de calagem para os Estados do Rio Grande e de Santa Catarina. 3. ed. Passo Fundo: Sociedade Brasileira de Ciência do Solo, 1994. 224 p.

COSTA, C. M. C.; MAIA, L. C.; CAVALCANTE, U. M. T.; NOGUEIRA, R. J. M. C. Influência de fungos micorrízicos arbusculares sobre o crescimento de dois genótipos de aceroleira (Malpighia emarginata D. C.). Pesquisa Agropecuária Brasileira, Brasília, v. 35, n. 4, p. 893-901, abr. 2001.

EMBRAPA. Centro Nacional de Pesquisa de Solos (Rio de Janeiro, RJ). Sistema brasileiro de classificação de solos. Brasília: Embrapa SPI/Embrapa CNPS, 1999. 412 p.

HAAS, J. H.; MENGE, J. A. VA mycorrhizal fungi and soil characteristics in avocado (Persea americana Mill.) orchard soil. Plant and Soil, The Hague, v. 127, n. 2, p. 207-212, Oct. 1990.

MENGE, J. A.; DAVIS, R. M.; JOHNSON, E. L. V.; ZENTMYER, G. A. Mycorrhizal fungi increase growth and reduce transplant injury in avocado. California Agriculture, Berkeley, v. 32, n. 4, p. 6-7, Apr. 1978.

MENGE, J. A.; LARUE, J.; LABANAUSKAS, C. K.; JOHNSON, E. L. V. The effect of two mycorrhizal fungi upon growth and nutrition of avocado seedlings grown with six fertilizer treatments. Journal of the American Society for Horticultural Science, New York, v. 105, n. 3, p. 400-404, July 1980.

NEMEC, S. Glomus intraradix effects on citrus rootstock seedling growth in various potting media. Journal of Agricultural Science, Cambridge, Inglaterra, v. 118, p. 315-323, June 1992.

POWELL, C. L.; BAGYARAJ, D. J. VA mycorrhiza. Boca Raton: CRC Press, 1984. 234 p.

SCHMITZ, J. A. K. Cultivo de Poncirus trifoliata L. Raf. em recipientes: influência de substratos e de fungos micorrízicos arbusculares. 1998. 144 f. Dissertação (Mestrado em Fitotecnia) - Universidade Federal do Rio Grande do Sul, Porto Alegre, 1998.

SILVA, L. F. C.; SIQUEIRA, J. O. Crescimento e teores de nutrientes de mudas de abacateiro, mangueira e mamoeiro sob influência de diferentes espécies de fungos micorrízicos vesículo arbusculares. Revista Brasileira de Ciência do Solo, Campinas, v. 15, n. 3, p. 283-288, set./dez. 1991.

SIQUEIRA, J. O. Micorrizas arbusculares. In: ARAUJO, R. S.; HUNGRIA, M. (Ed.). Microrganismos de importância agrícola. Brasília: Embrapa, 1994. p. 151-194.

SIQUEIRA, J. O.; FRANCO, A. A. Micorrizas. In: . Biotecnologia do solo: fundamentos e perspectivas. Brasília: MEC-ESAL, 1988. p. 125-177.

SOUZA, P. V. D. de; ABAD, M.; ALMELA, V.; AGUSTÍ, $M$. Efecto de sustrato de cultivo y hongos micorrízicos arbusculares sobre el desarrollo vegetativo y el contenido en carbohidratos en plantas de citrange troyer injertadas de mandarina Marisol. Revista Brasileira de Fruticultura, Cruz das Almas, v. 20, n. 2, p. 235-245, ago. 1998.

VIDAL, M. T.; AGUILAR, A.; BAREA, J. M.; PLIEGOALFARO, F. Mycorrizhal inoculation enhances growth and development of micropropagated plants of avocado. HortScience, Alexandria, v. 27, n. 7, p. 785-787, July 1992. 